\title{
February 2017 Critical Care Case of the Month
}

\author{
Morgan Wong, DO \\ Nicholas Villalobos, MD \\ Department of Internal Medicine \\ University of New Mexico \\ Albuquerque, NM USA
}

\section{History of Present IIIness}

A 68-year-old man presented to the emergency department with a one-day history of lower back pain, arthralgias, and malaise. The patient had a previous splenectomy and was concerned about influenza.

\section{Past Medical History, Social History, and Family History}

$\mathrm{He}$ has a history of osteoarthritis, seasonal allergies, and splenectomy. He is a nonsmoker. Family history is noncontributory.

\section{Physical Examination}

Upon admission, the patient's vital signs were notable for a temperature of 35.3 degrees Celsius, blood pressure of $74 / 44 \mathrm{mmHg}$, oxygen saturation of $85 \%$ on room air with a respiratory rate of 24 breaths per minute. Physical exam was prominent for non-pitting edema of the distal upper and lower extremities, as well as diffuse macular rash of the palms and soles.

\section{Laboratory}

$\mathrm{CBC}$

- White blood cell count of $6.77 \times 10^{3}$ cells/uL

- Hemoglobin of $13.8 \mathrm{gm} / \mathrm{dL}$

- Hematocrit of $43.7 \%$

- Platelet count of $19 \times 10^{3} / \mathrm{uL}$

Chemistry

- Creatinine of $3.0 \mathrm{mg} / \mathrm{dL}$

- $\mathrm{CO} 2<10 \mathrm{mmol} / \mathrm{L}$

- Anion gap $>18 \mathrm{mmol} / \mathrm{L}$

Liver function tests

- Alanine aminotransferase (ALT) of $511 \mathrm{U} / \mathrm{L}$

- Aspartate aminotransferase (AST) of $529 \mathrm{U} / \mathrm{L}$

- Total bilirubin of $1.0 \mathrm{mg} / \mathrm{dL}$

Coagulation

- INR of 2.07

- Prothromin time of 22.5 seconds

- Partial thromoboplastin time of 82.3 seconds

- Fibrinogen level was $71 \mathrm{mg} / \mathrm{dL}$

Arterial blood gases

- $\mathrm{pH}$ of 6.91 
- $\mathrm{pCO} 254 \mathrm{mmHg}$

- $\mathrm{pO} 2263$

- $\mathrm{HCO} 3$ of $7.7 \mathrm{mmol} / \mathrm{L}$

Procalcitonin $>200 \mathrm{ng} / \mathrm{ml}$.

His blood peripheral smear was examined.

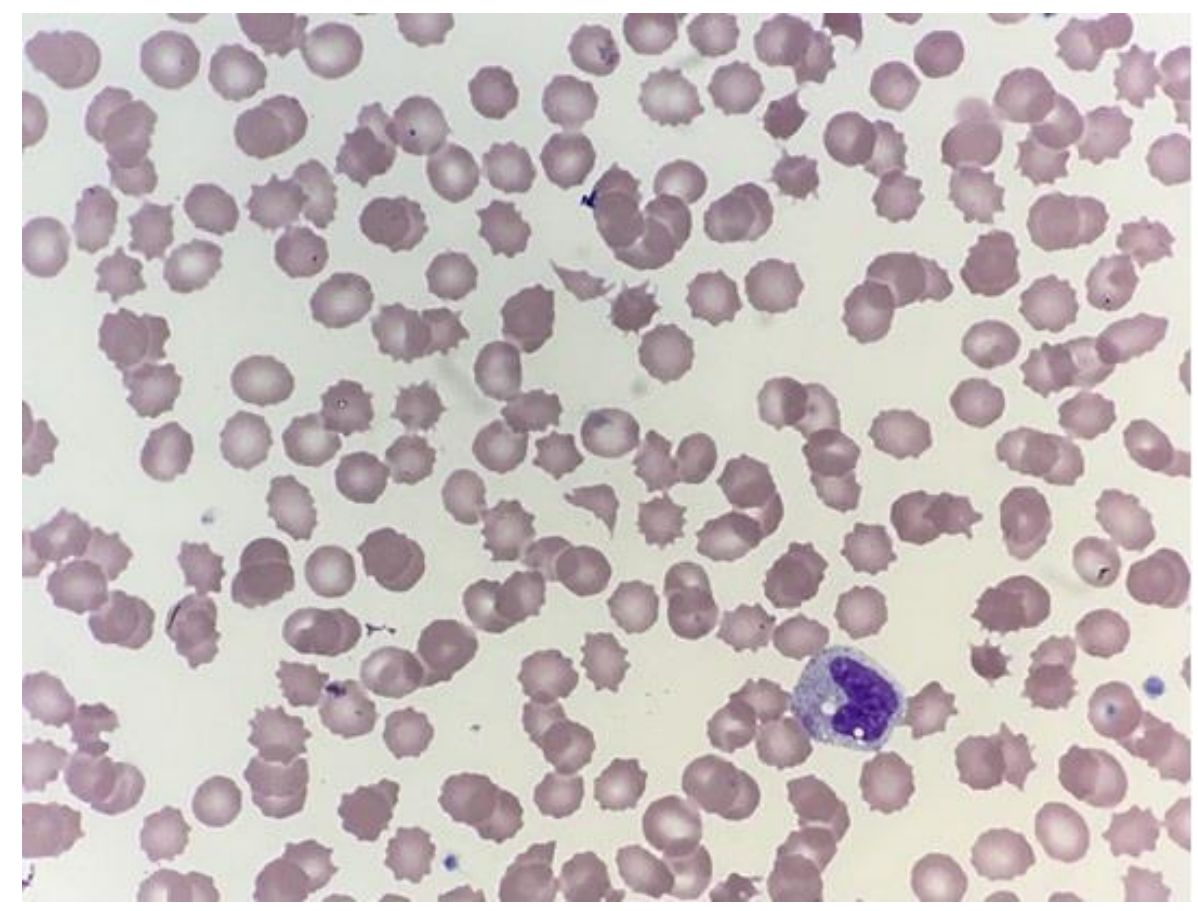

Figure 1: Peripheral blood smear on admission.

Given the results of the preliminary laboratory results and peripheral smear what hematologic abnormality are you most concerned with at this time?

1. Autoimmune hemolytic anemia (AlHA)

2. Disseminated intravascular coagulopathy (DIC)

3. Microangiopathic hemolytic anemia (MAHA)

4. Thrombotic thrombocytopenic purpura (TTP) 


\section{Correct! \\ 2. Disseminated intravascular coagulopathy (DIC)}

DIC is a pathological imbalance in the procoagulant and anticoagulant systems, which leads to unregulated thrombin generation (1). DIC is secondary to many states, including sepsis/infection, malignancy, and trauma. DIC classically presents with a low platelet count, elevated INR, elevated PT and PTT times, as well as a decreased fibrinogen level. Peripheral smear demonstrates shistocytes, and low platelet levels that are also reflective of DIC. Microangiopathic hemolytic anemia is incorrect given it typically presents with normalized PT, and PTT times, as well as normalized fibrin levels. Thrombotic thrombocytopenia purpura and autoimmune hemolytic anemia would be unlikely given the patient's normal bilirubin levels.

The patient was subsequently intubated and placed on norepinephrine for hypotension and piperacillin and tazobactam for presumed sepsis. Blood cultures were positive for gram-positive cocci in two out of two cultures. A lumbar puncture was performed which noted a total nucleate cell count of $1 / \mathrm{uL}$, glucose of $57 \mathrm{mg} / \mathrm{dL}$, protein $69 \mathrm{mg} / \mathrm{dL}$, with an HSV IgG of 0.12 . Lactic acid was $5.5 \mathrm{mmol} / \mathrm{L}$. Streptococcus pneumoniae antigen and urinary Legionella antigen were negative. Computed tomography (CT) scan of the brain, thorax, abdomen, and pelvis was notable for diffuse body wall edema as well as bilateral lower lobe atelectasis.

Given the patient's medical history and clinical presentation what organism would have likely precipitated the current presentation?

1. Haemophilus influenzae

2. Neisseria meningiditis

3. Streptococcus agalactiae

4. Streptococcus pneumoniae 


\section{Correct! \\ 3. Streptococcus agalactiae}

The patient presents with a history of splenectomy, making encapsulated organisms the most likely causative organism. Streptococcus agalactiae or Group B Streptococcus (GBS) is a gram positive encapsulated organism that has been documented to present with hypotension, coagulopathy, renal dysfunction, and erythematous rash (2). Streptococcus pneumoniae is unlikely given negative clinical history without notable findings on CT imaging, and negative streptococcal antigen. Neisseria meningitidis is unlikely given no sign of meningismus and a lumbar puncture with low cell count and normal glucose levels. Haemophilus influenzae is a gram-negative bacteria.

The resident astutely notes that a finger is necrotic distally (Figure 2).

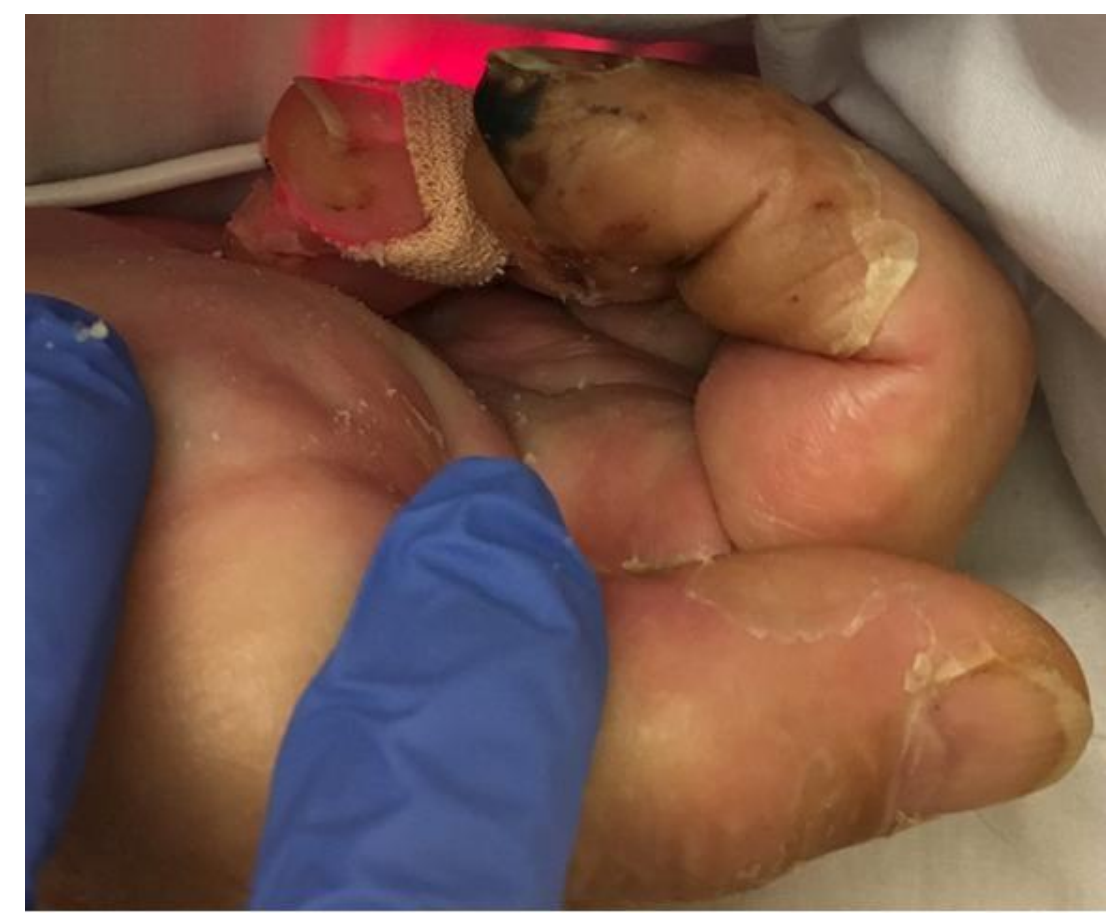

Figure 2. Photograph of patient's necrotic finger.

On further examination, the patient's toes are also necrotic.

What therapy would you initiate?
1. Dobutamine
2. Epoprostenol
3. Norepinephrine
4. Phentolamine 


\section{Correct! \\ 3. Norepinephrine}

The patient has dry gangrene from a myriad of causes to include possible hypothermia with potential frostbite injury, toxic shock secondary to group B Streptococcus, disseminated intravascular coagulopathy, and now with the addition of vasopressor support; potential vasospam. Group B Streptococcus has been shown to present with a toxic shock like syndrome (TSLS) from pyrogenic toxin(s) (2-4). The goal in therapy is to treat the underlying disease but preservation of the extremity is pivotal. In this case, continuation of norepinephrine with a plan to discontinue as soon as possible is the most appropriate plan (5). Phentolamine is incorrect as there is no evidence of pressor extravasation. There is limited evidence for the use of epoprostenol used solely as reversal for vasospasm. Dobutamine at this time is not a preferred vasopressor.

Once you receive speciation, what antibiotics should be added or augmented?

1. Addition of ampicillin and sulbactam and discontinuation of piperacillin and tazobactam

2. Addition of cefepime and discontinuation of piperacillin and tazobactam

3. Addition of cefepime only

4. Addition of clindamycin 


\section{Correct! \\ 4. Addition of clindamycin}

The addition of clindamycin for its inhibition of bacterial protein synthesis is crucial to reduce the severity of the disease (2-4). Linezolid otherwise, would be preferred in areas of high clindamycin resistance. The other choices do not act specifically to inhibit protein synthesis.

The mortality rate of toxic shock like syndrome secondary to Group B Streptococcus agalactiae approaches $50 \%$ in review of current literature with rates of infection anywhere from 22 to 30 per 10,000 patients per population (24). There are no current vaccinations available to patients for prevention of this encapsulated organism like there is for Haemophilus influenza, Neisseria meningiditis, and Streptococcus pneumoniae.

\section{References}

1. Levi M, Ten Cate H. Disseminated intravascular coagulation. N Engl J Med. 1999 Aug 19;341(8):586-92. [CrossRef] [PubMed]

2. Al Akhrass F, Abdallah L, Berger S, Hanna R, Reynolds N, Thompson S, Hallit R, Schlievert PM. Streptococcus agalactiae toxic shock-like syndrome: two case reports and review of the literature. Medicine (Baltimore). 2013 Jan;92(1):10-4. [CrossRef] [PubMed]

3. Shenoy R, Agarwal N, Goneppanavar U, Shenoy A, Sharma A. Symmetrical peripheral gangrene-a case report and brief review. Indian J Surg. 2013 Jun;75(Suppl 1):163-5. [CrossRef] [PubMed]

4. Sims KD, Barton TD. Group B streptococcal toxic shock syndrome in an asplenic patient: case report and literature review. Eur J Clin Microbiol Infect Dis. 2006 Mar;25(3):208-10. [CrossRef] [PubMed]

5. Gelinas JP, Russell JA. Vasopressors during sepsis: selection and targets. Clin Chest Med. 2016 Jun;37(2):251-62. [CrossRef] [PubMed] 